\title{
Left ventricular filling and early diastolic function
rest and during angina in patients with coronary artery disease
}

\author{
J R DAWSON, D G GIBSON \\ From the Brompton Hospital, London
}

SUMMARY Left ventricular diastolic function was studied in 11 patients with coronary artẹpy disease. Single plane ventriculography ( $30^{\circ}$ right anterior oblique projection) was performed at rist and during an episode of angina immediately after a period of rapid atrial pacing. Left ventricufor pressure was recorded simultaneously by a micromanometer tipped catheter. The ventriculograms were digitised frame by frame to derive continuous plots of left ventricular shape, volume, and rate of change of volume. The time constant $(\tau)$ of the fall in left ventricular pressure was determin\&d from the exponential portion of pressure decay during isovolumic relaxation. Ventricular pressurevolume loops were constructed to study the left ventricular diastolic pressure-volume relation. T $\overrightarrow{B e}$ time of minimum left ventricular pressure was used to divide diastole into an early phase and a láte phase. Angina was associated with an increase in end systolic volume and a fall in ejection fractiog with no significant change in end diastolic volume. Peak left ventricular pressure was unchange but left ventricular minimum and end diastolic pressures were both increased and the diastoकic pressure-volume relation was moved upwards. The time constant of left ventricular pressure fiêd was prolonged. At rest more than $50 \%$ of the stroke volume entered the left ventricle during the period of early diastole. This proportion was significantly reduced during angina and aş्. consequence a significantly greater proportion of the stroke volume entered the ventricle during late diastole. Despite this, and although the left ventricular diastolic pressure-volume relation was moved upwards with angina, the mean slope of the relation during late diastole-that is, chamber stiffness - was not significantly altered. The upward shift of the left ventricular diastolic pressurevolume relation seen during angina is thus already apparent in early diastole, and its extent does not change during the later phase of diastole, which alone shows the property of passive stiffness. $\mathrm{A}$ primary increase in the passive stiffness of the ventricle cannot therefore be the cause of the upwaid shift of the diastolic pressure-volume relation, and events occurring in early diastole have to be looked to for an explanation.

The study findings show that left ventricular function in early diastole is profoundly disturbed during angina pectoris and it is suggested that loss of elastic recoil and dissipation of this restoriang force by asynchronous onset of relaxation and abnormal changes in shape are important factofs contributing to this disturbance of function.

An increase in left ventricular end diastolic pressure and an upward shift of the left ventricular diastolic pressure-volume relation are well recognised haemodynamic consequences of myocardial ischaemia. ${ }^{12}$ Various explanatory mechanisms have

Requests for reprints to $\mathrm{Dr} J \mathrm{R}$ Dawson, Brompton Hospital, Fulham Road, London SW3 6HP.

Accepted for publication 5 December 1988 been postulated, including loss of elastic recoil ${ }^{34}$ and dissipation of this restoring force by asynchronews wall motion during ventricular relaxation, ${ }^{56}$ exterfal restraint of the left ventricle by the right ventricle and a constraining pericardium, ${ }^{7}$ and, most frequenthy cited, increases in chamber stiffness due either 90 delayed deactivation of actin-myosin cross bridgesan ischaemic regions of the myocardium ${ }^{89}$ or $\mathbb{g}_{0}$ increased myocardial turgor. ${ }^{10}$ Ventricular relaxation 
and filling, however, are such complex processes that they are unlikely to be determined by any single factor and it is probable that each of these mechanisms affects function at some time during the diastolic period. In the present study therefore we used the point of minimum left ventricular pressure to divide diastole into an early and a late phase to try to understand how in patients with coronary artery disease an episode of angina induced by rapid atrial pacing modifies left ventricular function in early diastole, and the effect these abnormalities have on later diastolic events.

\section{Patients and methods}

\section{PATIENTS AND CATHETERISATION PROCEDURE}

Studies were performed at the time of diagnostic catheterisation in 11 male patients (mean age 52 years, range 42-68 years). All patients had chronic stable exertional angina and all had appreciable $(>70 \%$ ) obstructive coronary artery disease (four single, one double, and six triple vessel disease). Four of the patients had had a previous myocardial infarction. All medications, except glyceryl trinitrate, were stopped at least 15 hours before catheterisation, which was performed without premedication.

The study protocol was approved by the ethics committee of the Brompton Hospital and involved the performance of two left ventricular cineangiograms - the first at rest and the second during an episode of angina induced by rapid atrial pacing. The two cineangiograms were performed at least 20 minutes apart and on each occasion we used identical cine frame speeds (50/second), radiographic projections ( $30^{\circ}$ right anterior oblique), quantities of contrast agent $(50 \mathrm{ml}$ of Urografin 370 , meglumine diatrizoate), and flow rates $(12 \mathrm{ml} / \mathrm{s})$. Unfiltered high fidelity left ventricular pressure was measured during each contrast injection by a Gaeltec catheter tip pressure transducer and was recorded, together with an electrocardiogram, on a strip chart at a paper speed of $200 \mathrm{~mm} / \mathrm{s}$. The micromanometer signal was calibrated by superimposing it on a left ventricular pressure pulse derived from a conventional fluid filled manometer system.

To provoke an episode of angina patients were paced from the right atrial appendage with a Zucker pacing catheter. Pacing was initiated at 100 beats $/ \mathrm{min}$ and the rate was increased by 10 beats/min every two minutes up to a maximum of 150 beats $/ \mathrm{min}$. When the patient indicated that he was experiencing angina of an intensity at which he would normally need to rest or to take a glyceryl trinitrate tablet, pacing was abruptly stopped and the second left ventricular cineangiogram was performed almost immediately (5-10 seconds later) with the patient in sinus rhythm.
ANALYSIS OF DATA

The left ventricular cineangiograms were digitised frame by frame. ${ }^{11} \mathrm{~A}$ calibration value was obtained by displacing the catheter table $10 \mathrm{~cm}$. Frames were related to each other by means of a fixed external reference point. ${ }^{12}$ Beats used for analysis had occurred within five cycles from the start of contrast injection (when the effects of contrast on left ventricular function are negligible ${ }^{13}$ ), showed complete cavity opacification, and were not postextrasystolic. A mark on the cinefilm produced by an electrocardiographically gated light emitting diode in the cinecamera shutter plane assembly enabled the end diastolic frame to be identified. Plots were generated (fig 1) to show the following variables continuously
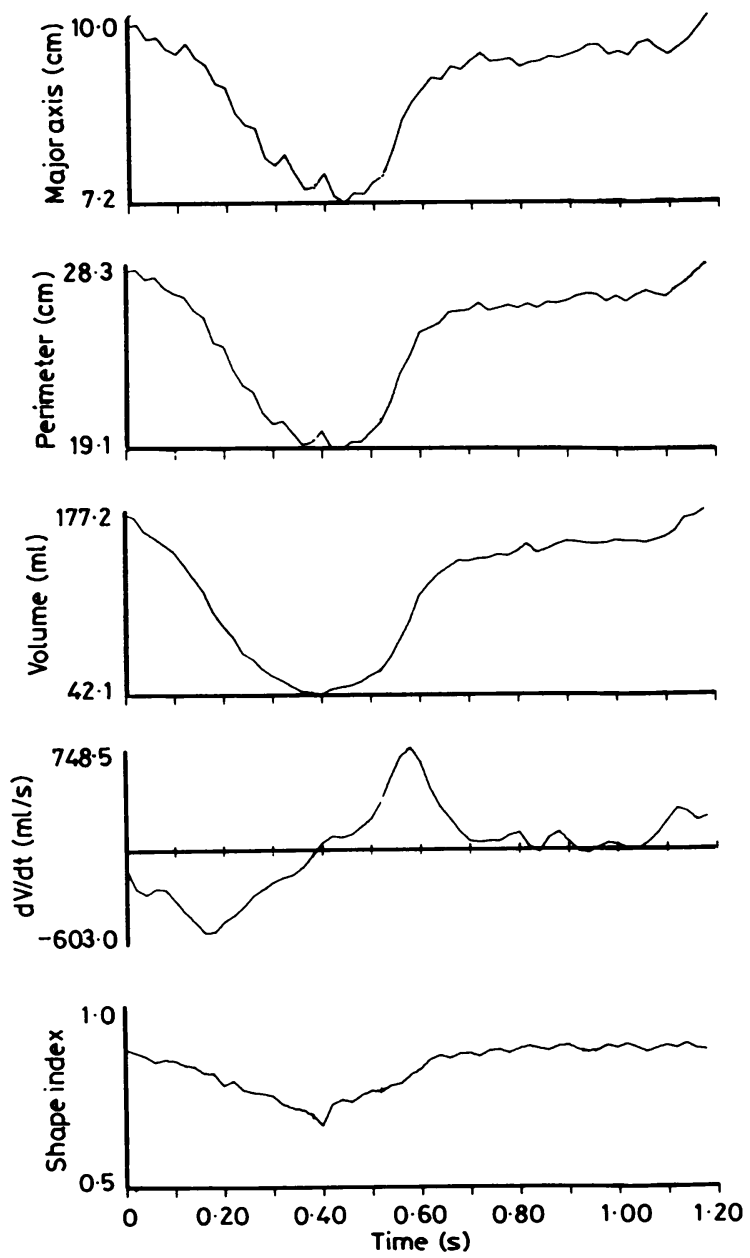

Fig 1 Computer generated plot showing changes in length of the ventricular major axis, ventricular perimeter length, ventricular volume, rate of change of ventricular volume $(d V / d t)$, and shape index during the cardiac cycle. 
throughout the cardiac cycle: the length of the ventricular major axis, the length of the cavity perimeter, the ventricular volume (derived using the area-length method ${ }^{14}$ ), the rate of change of volume, and a shape index. The shape index ${ }^{15}$ was calculated by the formula $4 \pi$ (area)/perimeter ${ }^{2}$. It expresses how nearly the ventricular cavity outline in the plane being studied resembles a circle, which has a shape index with a value of one. Mitral valve opening was taken as occurring at the time of the frame immediately preceding the frame that first showed unopacified blood entering the left ventricle during diastole. A marker on the paper chart recorder that showed the onset of contrast injection allowed the high fidelity pressure trace for the beat being analysed to be identified. The pressure trace was digitised (200 Hz sampling frequency) and plots were generated to show pressure during the cardiac cycle and the rate of change of pressure $(\mathrm{dP} / \mathrm{dt})$ with time. The time constant $(\tau)$ of diastolic isovolumic left ventricular pressure decay was calculated from a plot of the natural $\log$ of pressure $(P)$ with time, which assumes the pressure asymptote to be zero. ${ }^{16}$ The time at which left ventricular pressure reached a minimum value (Pmin) was taken as the point at which the plot of $\mathrm{dP} / \mathrm{dt}$ reached the zero baseline in diastole.

Regional wall motion was studied by analysing the motion of $\mathbf{4 0}$ separate points equally spaced around the perimeter of the left ventricular cavity. We used established normal limits for the amplitude and Table 1 Pressure data timing of wall motion to identify regional hyp:kinesis and asynchrony. ${ }^{17}$

The start of diastole was defined as the time of peak negative dP/dt and the end was taken to be the time of onset of the electrocardiographic $Q$ wave of the following beat. The time of minimum left ventricu屃r pressure was used to divide diastole into an early a id a late phase. The following were measured:

(a) Left ventricular peak systolic pressure, eñ๊d diastolic pressure, pressure at the time of mitral valte opening (Pmvo), and minimum pressure (Pmin).

(b) The time constant $(\tau)$ of left ventricular pressure decay during isovolumic relaxation.

(c) The maximum rate of change of pressure during pressure rise $(+\mathrm{dP} / \mathrm{dt})$ and presure fall $(-\mathrm{dP} /$ dt).

(d) Left ventricular end diastolic volume (sy chronous with the onset of the $Q$ wave on the electrocardiogram), end systolic volume (minimum volume), and volume at Pmin.

(e) Left ventricular stroke volume and ejectiân fraction.

$(f)$ The respective volumes entering the left ventricle during early diastole and late diastege expressed in absolute terms and as a percentage of the total stroke volume.

(g) The maximum rate of increase of left vemtricular volume during diastole (peak $\mathrm{dV} / \mathrm{dt}$ ).

(h) Left ventricular shape index at end diasto end systole, and at Pmin.

(i) The length of the left ventricular major axis $\overrightarrow{\vec{a}}$

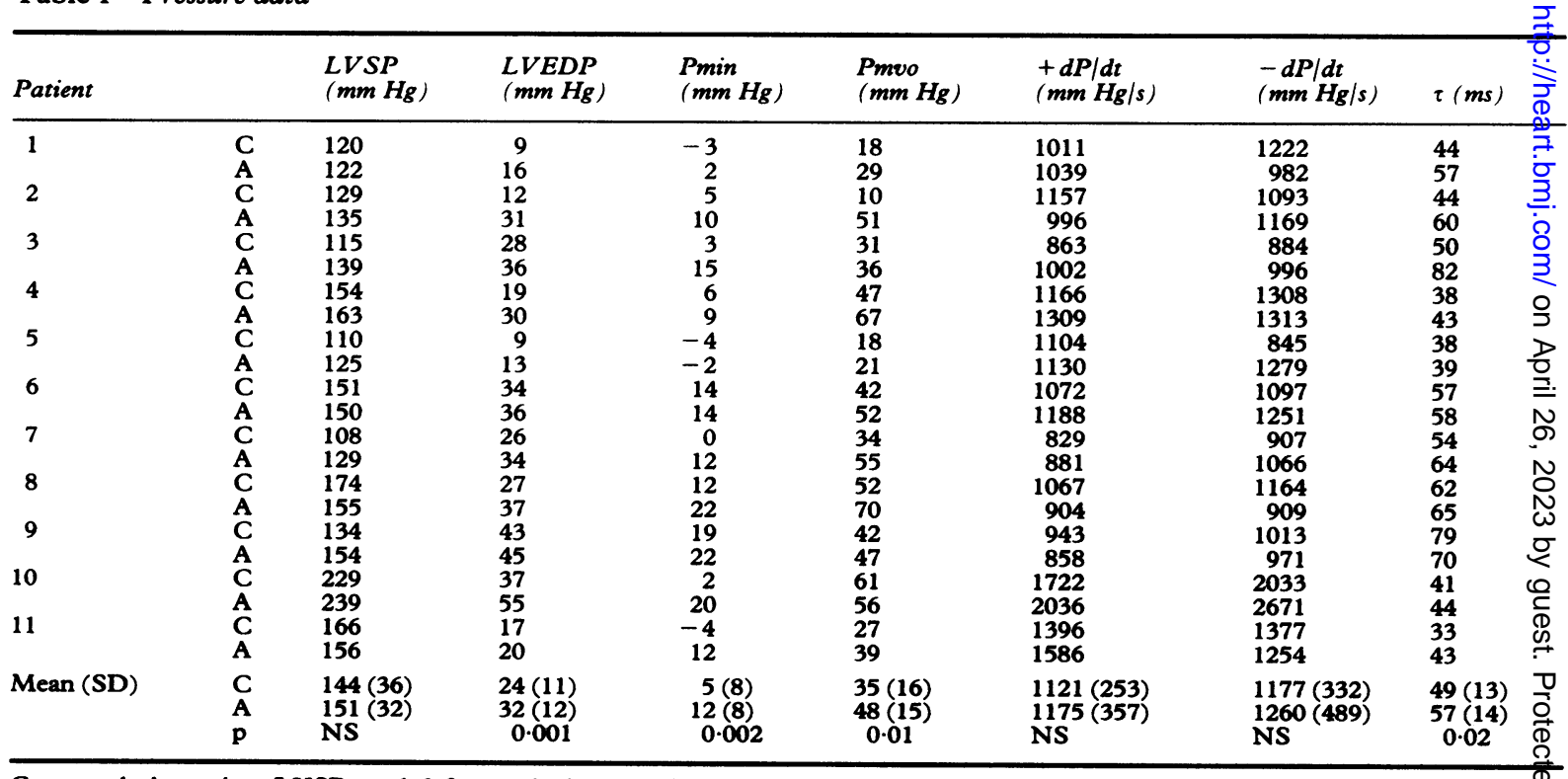

C, control; A, angina; LVSP, peak left ventricular systolic pressure; LVEDP, left ventricular end diastolic pressure; Pmin, minimim pressure; Pmvo, pressure at time of mitral valve opening; dP/dt, peak rate of change of left ventricular pressure; $\tau$, time constant 6 f pressure fall in early diastole. 
end diastole, end systole, and at Pmin. This was defined as the distance from the mid point of the aortic root to the most distant point on the cavity perimeter.

(j) Time intervals: cycle length; $Q-$ peak negative $\mathrm{dP} / \mathrm{dt} ; \mathrm{Q}$ - mitral valve opening; $\mathrm{Q}$ - peak $\mathrm{dV} / \mathrm{dt}$; and $\mathrm{Q}-\mathrm{Pmin}$.

\section{STATISTICAL METHODS}

Results are expressed as mean (1 SD). Differences between means were compared by Student's paired $t$ test. A p value of $<0.05$ was regarded as significant.

\section{Results}

Figures 2 and 3 and tables 1-3 show the measurements made at rest and during angina of pressure and volume and the indices derived from them. Mean heart rate in the group was significantly higher during angina at the time of the second angiogram (72 (19) beats/min) than at rest (64 (11) beats/min) $(p<0.01)$. In three of the 11 patients (cases 3, 8, and 9) heart rate either decreased or was unchanged during angina.

PRESSURE DATA (TABLE 1)

Left ventricular peak systolic pressure was unchanged by angina but pressures were raised throughout the period of diastole. Left ventricular end diastolic pressure rose by $8(6) \mathrm{mm} \mathrm{Hg}(\mathrm{p}<0.001)$ as did minimum left ventricular pressure by 8 (6) $\mathrm{mm} \mathrm{Hg}$ (p $<0.005)$. Left ventricular pressure at the time of mitral valve opening rose by 13 (12) $\mathrm{mm} \mathrm{Hg}$ (p < 0.01 ). Peak $d P / d t$ and peak negative $d P / d t$ were unchanged by angina.

The time constant $(\tau)$ of pressure decay during isovolumic relaxation was 49 (13) $\mathrm{ms}$ at rest and increased to $57(14) \mathrm{ms}$ during angina $(\mathrm{p}<0.02)$.

VOLUME DATA (TABLE 2)

The left ventricular end diastolic volume was unchanged by angina but there was a small though significant rise in minimum volume from 44 (17) $\mathrm{ml}$ at rest to $54(18) \mathrm{ml}$ during angina $(\mathrm{p}<0.01)$. In consequence, the ejection fraction fell by $5(6) \%$ (p $<0.05$ ). Changes in stroke volume were inconsistent, although there tended to be a fall with angina. The left ventricular volume at the time of minimum left ventricular pressure was $110(34) \mathrm{ml}$ at rest and 106 (30) $\mathrm{ml}$ with angina (NS). Figure 2 shows the relation between left ventricular pressure and volume at the time of minimum left ventricular pressure at rest and during angina in individual patients. In most patients at this moment in the cardiac cycle the pressure-volume point is moved upwards and sometimes leftwards during angina, indicating a higher intracavity pressure for a given volume. The upward movement was statistically significant, the lateral movement (that is volume change) was not. At rest the volume of blood entering

Table 2 Volume data

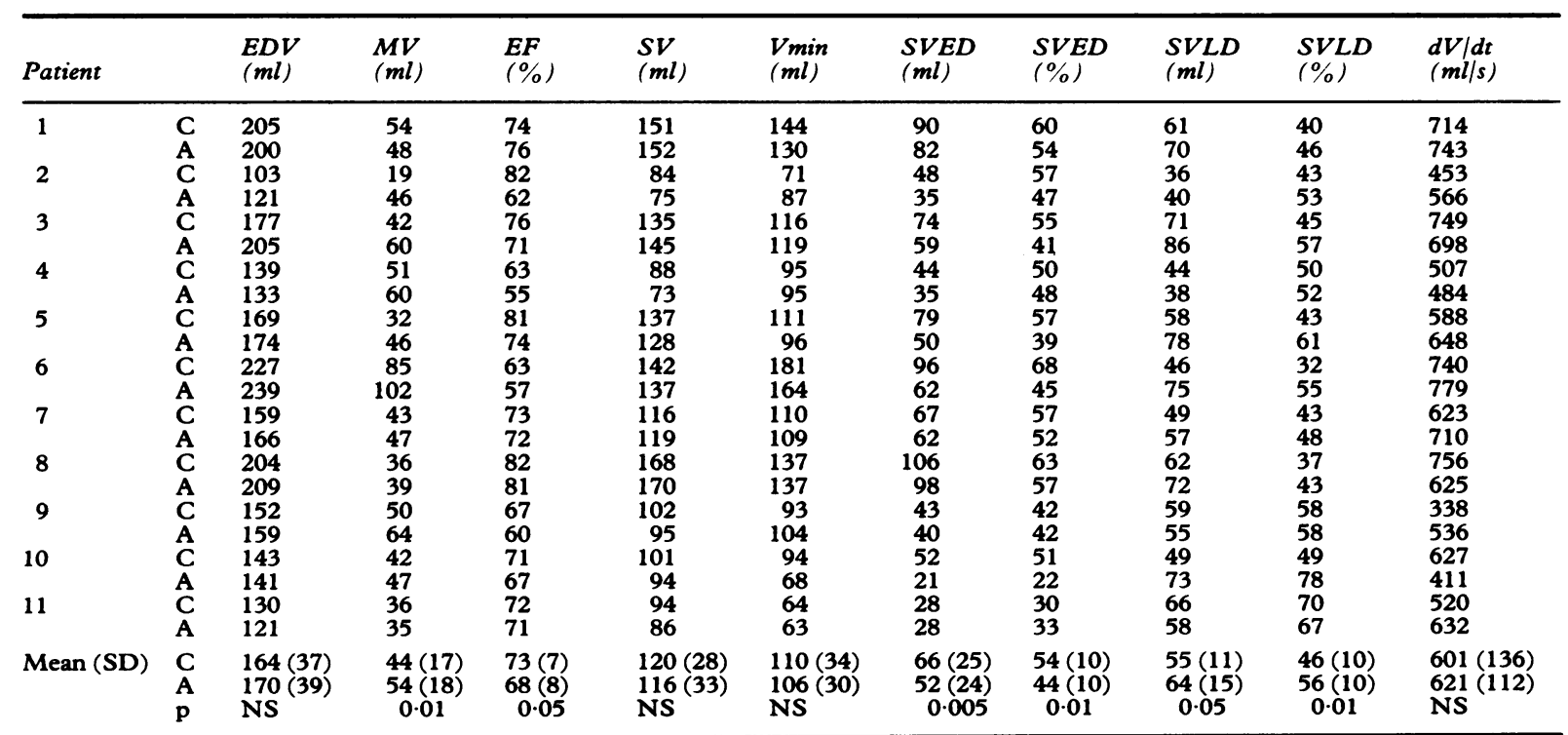

C, control; A, angina; EDV, end diastolic volume; MV, minimum volume; EF, ejection fraction; SV, stroke volume; Vmin, volume at time of minimum pressure; SVED, stroke volume entering left ventricle during early diastole; SVLD, stroke volume entering left ventricle during late diastole; $\mathrm{dV} / \mathrm{dt}$, peak rate of volume increase during diastole. 


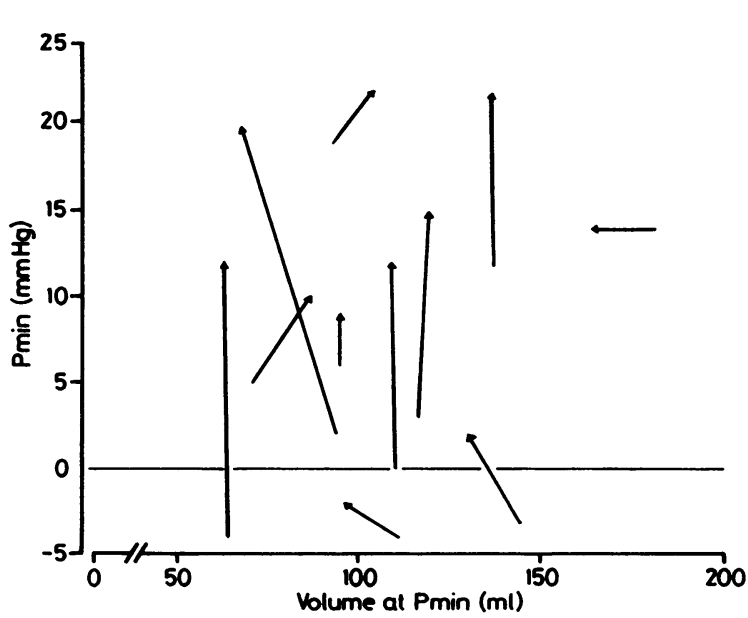

Fig 2 Left ventricular pressure-volume relations at the time of minimum left ventricular pressure. The arrows represent the change in this relation with an episode of angina in individual patients.

the left ventricle during early diastole was $66(25) \mathrm{ml}$ and during late diastole it was 55 (11) $\mathrm{ml}$, comprising respectively $54(10) \%$ and $46(10) \%$ of the total stroke volume. Angina was associated with a significant fall in the volume of blood entering the left ventricle during early diastole when expressed either in absolute $(14(12) \mathrm{ml} ; \mathrm{p}<0.005)$ or percentage terms $(10(10) \%, p<0.01)$. In consequence, during angina, significantly more blood, either in absolute $(p<0.05)$ or percentage terms $(p<0.01)$ entered the left ventricle in late diastole than at rest. Despite the reduction in ventricular inflow volume during early diastole the peak rates of volume inflow were unchanged.

Figure 3 shows the pressure-volume relations for individual patients at rest and during angina at the time of Pmin and at end diastole. During angina in 10 of the 11 patients there was an upward shift of the diastolic pressure-volume relation in this period of late diastole but, with the exception of patients 2 and 4, this shift was apparent at the start of late diastole and during late diastole no further divergence of the two relations was seen; in fact in three patients convergence of the relation was apparent. Thus in the group overall the rise in left ventricular end diastolic pressure induced by angina was virtually identical in magnitude with the rise in Pmin, and yet, during the period of late diastole bounded by these two times, a proportionally greater volume of blood entered the left ventricle than in the resting state. The values for the ratio of the change in pressure to the change in volume during late diastole $(\Delta \mathrm{P} / \Delta \mathrm{V})$ are shown with each plot. $\Delta \mathrm{P} / \Delta \mathrm{V}$ calculated in this way measures ventricular stiffness during late diastole when filling is passive. The mean $\Delta \mathrm{P} / \Delta \mathrm{V}$ for the 11 patients $\frac{\mathrm{N}}{\mathrm{Wa}}$ $0.355(0.16) \mathrm{mm} \mathrm{Hg} / \mathrm{ml}$ at rest and $0.331(0.147) \mathrm{mm}$ $\mathrm{Hg} / \mathrm{ml}$ during angina (NS).

LEFT VENTRICULAR GEOMETRY (TABLE 3)

The left ventricular end diastolic shape index wers unchanged by angina. The shape index at minimu volume rose by $0.019(0.019)(p<0.01)$ during angina, indicating that the ischaemic ventricle was more spherical at end systole. There was also a tremd for the shape index at the time of minimum pressute to increase with angina, but this was not statisticaty significant.

The lengths of the left ventricular major axis at exd diastole and at the time of minimum volume we्fre both significantly increased during angina ( $p$ i 0.05 ). At the time of minimum pressure the length $f$ the major axis was similar at rest and during angiga. When the length of the major axis at minimum pressure was expressed as a percentage of the tomal change in length during diastole, however, there was a significant reduction of $10(9) \%(p<0.01)$ during angina. Thus angina is associated with the develo $\overrightarrow{0}-$ ment of an abnormal pattern of ventricular diastofic shape change that is manifested by early assumption of a spherical configuration related to a delayed increase in the major axis of the ventricle.

TIME INTERVALS (TABLE 4)

The times of $Q$ to peak negative $d P / d t, Q$ to mitral valve opening, $Q$ to peak rate of volume increase during diastole, and $Q$ to minimum left ventricular pressure were all unchanged by angina. Figure 4 shows the mean for the time relations between peiak negative $\mathrm{dP} / \mathrm{dt}$, mitral valve opening, peak rate volume increase, and minimum left ventricular pressure at rest and during angina in the 11 patiens Angina did not significantly alter these time relations although there was an obvious shortening of the interval between peak rate of volume increase and minimum left ventricular pressure and lengthening of the interval between peak negative $\mathrm{dP} / \mathrm{dt}$ afd mitral valve opening, which approximates to te period of isovolumic relaxation. The duration of $\mathrm{f}$ early diastolic filling (mitral valve opening to mipjmum left ventricular pressure) fell from 134 (47) ( at rest to 106 (46) ms during angina but this change was not significant either in absolute terms or when expressed as a percentage either of the total filling period or of the cardiac cycle.

EFFECT OF REGIONAL WALL MOTION ABNORMALITIES

Angina induced regional wall motion abnormalities in all of the patients. Nine patients developed regions of hypokinesis (mean number of affected segmexts 

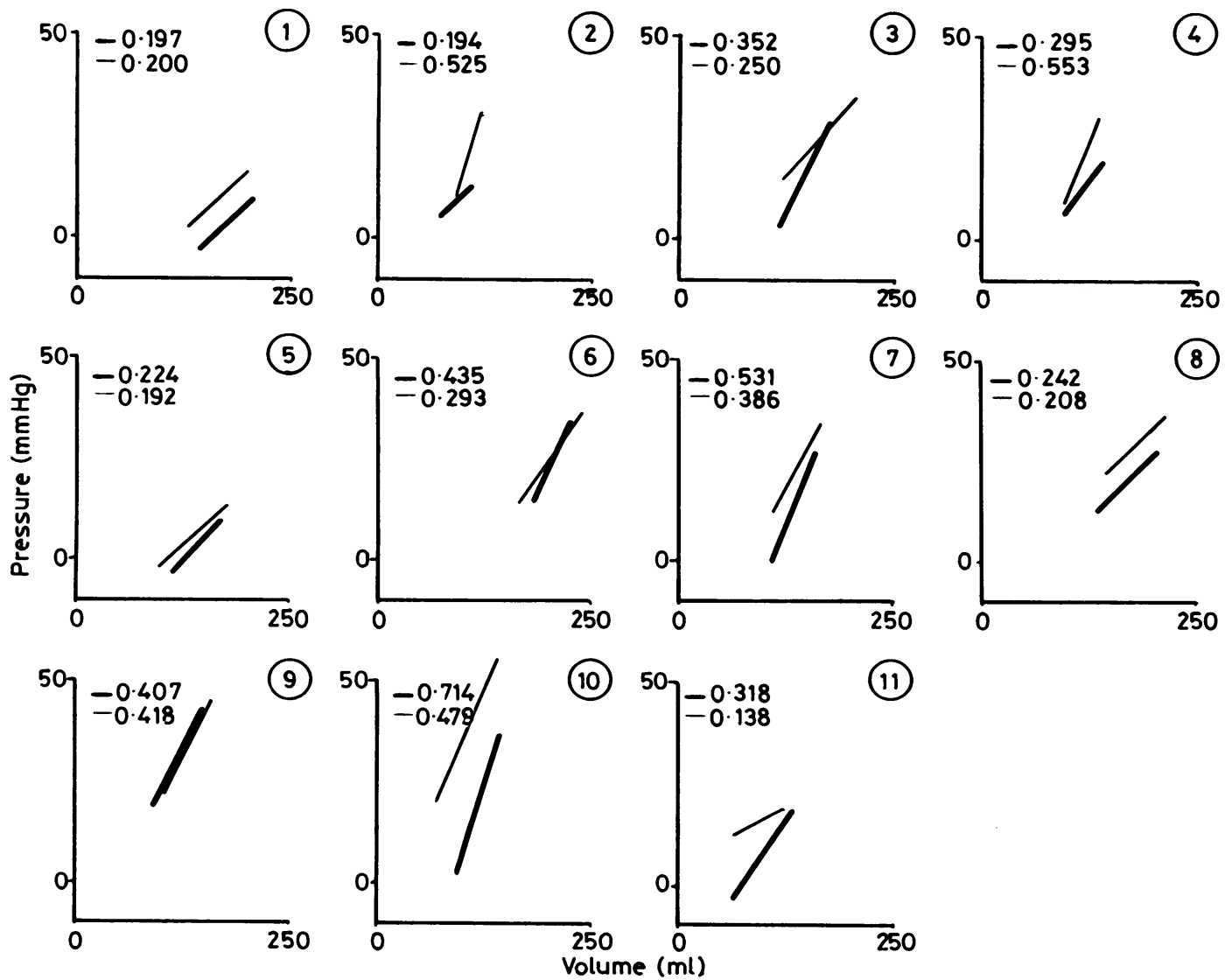

Fig 3 Pressure-volume relations during late diastole at control (bold lines) and during angina in 11 patients. For each plot, pressure ( $\mathrm{mm} \mathrm{Hg}$ ) is on the ordinate and volume ( $\mathrm{ml}$ ) on the abscissa. The values displayed at the top left hand corner of each plot indicate the mean slope ( $\mathrm{mm} \mathrm{Hg} / \mathrm{ml}$ ) of the pressure volume relation during late diastole which is a measure of left ventricular chamber stiffness.

six, range 3-12). Seven patients developed regions of asynchrony (mean number of affected segments six, range 5-9), either in isolation (two cases) or in association with hypokinesis (five cases). There was no discernible relation between the presence or extent of either kind of regional wall motion abnormality and the development of, or the magnitude of, altered measurements of left ventricular early diastolic function including changes in left ventricular geometry.

\section{Discussion}

The purpose of this study was to investigate the effects of an attack of angina on events in early diastole. Early diastole was taken as the time between peak negative $\mathrm{dP} / \mathrm{dt}$ and minimum left ventricular pressure. It thus included a period of isovolumic relaxation and most of the ventricular rapid filling period, the time of peak inflow being recorded before minimum pressure. Left ventricular pressure decay during isovolumic relaxation is exponential, which means that its rate can be measured as a time constant. ${ }^{16}$ Minimum left ventricular pressure represents the point at which ventricular pressure and volume begin to increase together-that is to show simple passive behaviour-so that only from this time can the slope of the pressure-volume relation be used as a measure of ventricular cavity stiffness.

We found that an attack of angina consistently affected early diastole. As in previous studies, ${ }^{18}{ }^{19}$ the time constant of the fall in left ventricular pressure was increased. A reduction in the rate of pressure fall would be predicted to prolong the periods of isovolumic relaxation and early diastole. However, this was not seen, probably because its effects were cancelled out by a simultaneous increase in ven- 
Table 3 Left ventricular geometry

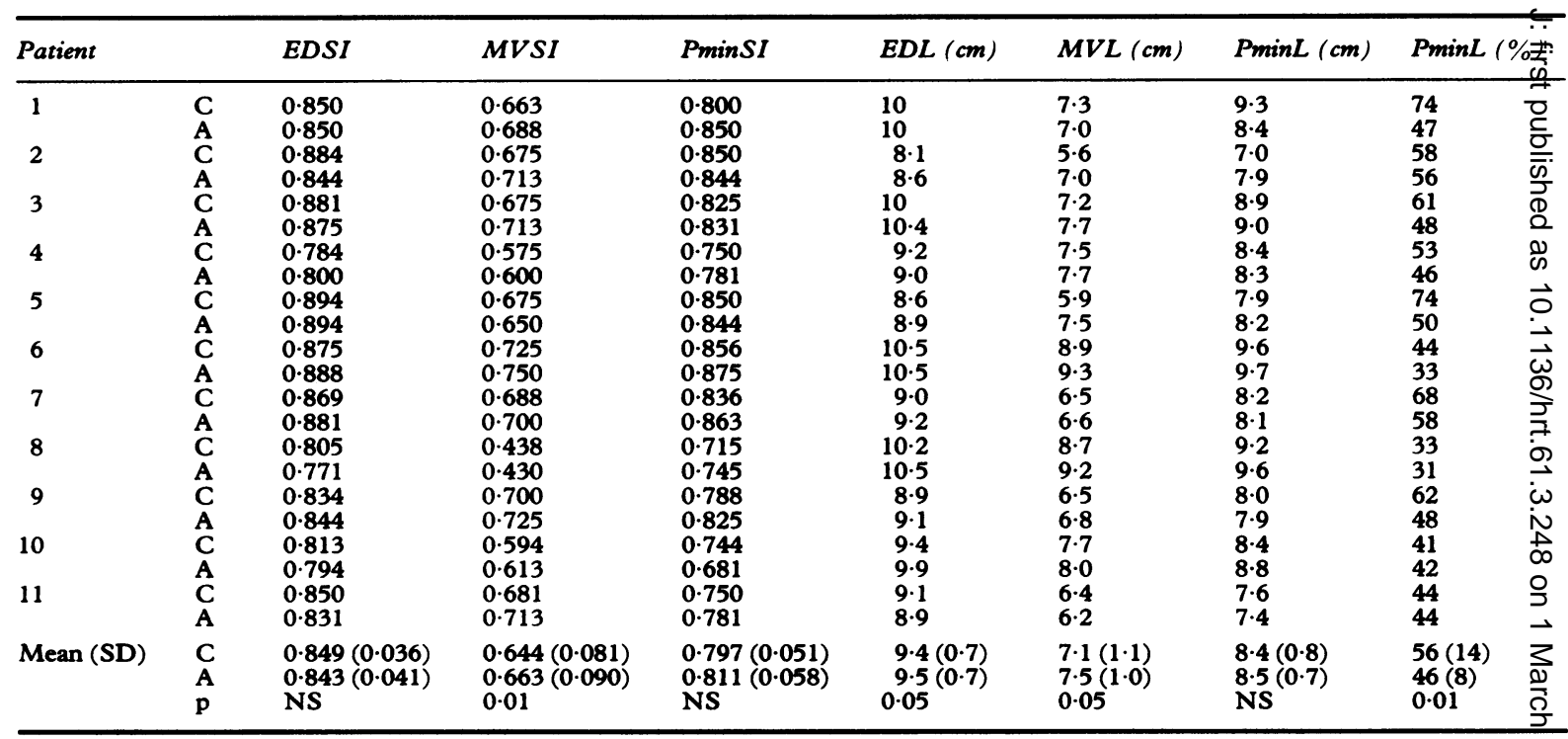

C, control; A, angina; EDSI, end diastolic shape index; MVSI, shape index at minimum volume; PminSI, shape index at time $\overrightarrow{0}$ f minimum pressure; EDL, length of long axis at end diastole; MVL, length of long axis at minimum volume; PminL, length of long axiggat time of minimum pressure.

tricular diastolic pressure, which has previously been shown to have a strong inverse correlation with isovolumic relaxation time. ${ }^{20}$ Not only was the duration of early filling unaffected by angina but also the time relations between early diastolic events seemed unchanged although it should be borne in mind that the timing of mitral valve opening was derived from angiography and is thus liable to error because of the interval $(20 \mathrm{~ms})$ between cine frames. We were unable to detect any discernible relations between the time constant of pressure fall or the changes in the time constant induced by ischaemia and any other manifestation of left ventricle diastolic function.

In control conditions, we found that just over half the stroke volume entered the left ventricle before the time of minimum left ventricular pressure; this value was rather higher than that previously reported. ${ }^{21} 22$ Angina consistently reduced this early diastolic inflow, both in relative and absolute terms; although

Table 4 Mean (SD) time intervals (ms)

\begin{tabular}{lll}
\hline & Control & Angina \\
\hline $\begin{array}{l}\text { Cycle length } \\
\text { Q to peak negative dP/dt }\end{array}$ & $944(161)^{\star}$ & $829(222)^{\star}$ \\
$\begin{array}{l}\text { Q to mitral valve opening } \\
\text { (MVO) }\end{array}$ & $413(36)$ & $398(48)$ \\
$\begin{array}{l}\text { Q to peak rate of } \\
\text { volume increase (dV/dt) }\end{array}$ & $538(47)$ & $436(47)$ \\
$\begin{array}{l}\text { to minimum ventricular } \\
\text { pressure }\end{array}$ & $572(49)$ & $542(72)$ \\
\hline p $<0.01$. & &
\end{tabular}

the duration of early diastole was not significar ly reduced and the timing of minimum pressure ${ }_{\text {in }}$ relation to peak inflow rate was maintained. A a corollary the proportion of stroke volume entering the left ventricle during late diastole was significantly increased. Angina increased ventricular cavity prossures throughout diastole; and the increases at the times of mitral valve opening, minimum pressute, and end diastole were statistically significant. Cavity geometry also changed; end systolic volume rose, ghe shape index indicated that the cavity was möre spherical, and lengthening of the ventricular lofig axis during early diastole was delayed.

In the present study the heart rate during angina was on average eight beats/min higher than the resting value, raising the question of whether the changes we saw and ascribed to angina were in flct merely secondary to a rate change. An increase-in heart rate is characteristically associated with shottening of the diastolic period. Inspection of pur results clearly shows that it was the period of diastole that was principally shortened. The duration of early diastole was unchanged by angina: $16.8 \%$ of the total cardiac cycle at control and $17.4 \%$ durimg angina. A combined analysis of our study patient S $^{\mathrm{D}} \mathrm{at}$ rest and a further 10 normal subjects studied in our laboratory showed that, over the range of heart rgte found in our study, the duration of early diast面le seems to have no consistent relation with cycle len fith $(r=0 \cdot 25)$. Finally, in three of our patients $(3,8$, and 9) cycle length either increased or was unchanged 
Conrroc

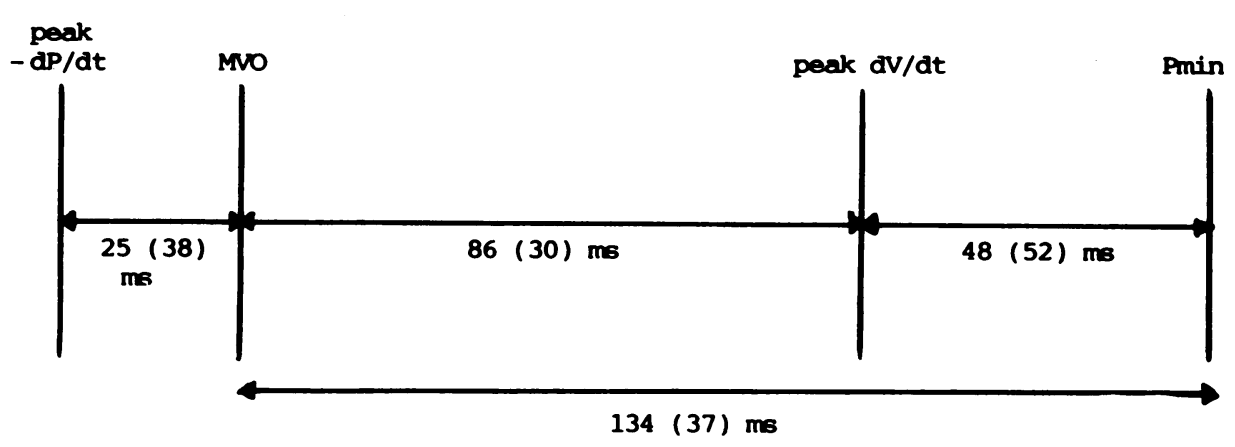

ANGINA

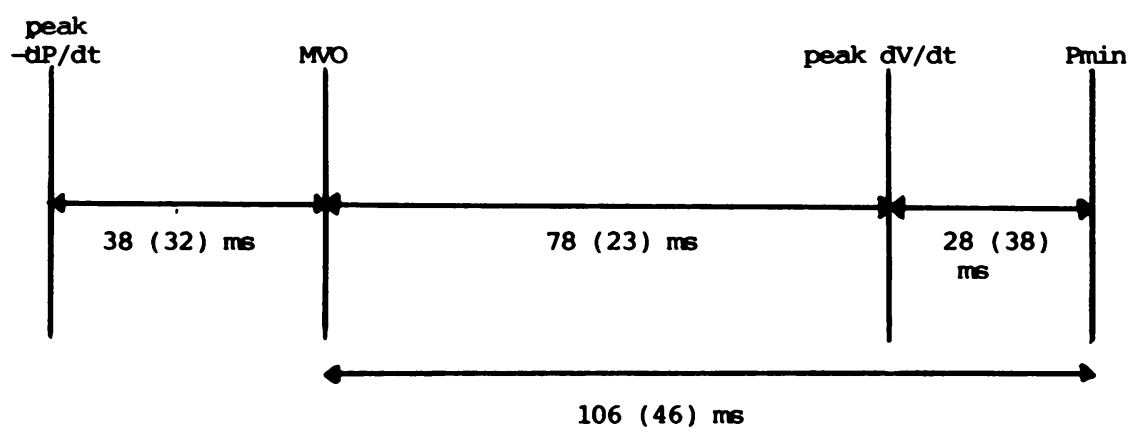

Fig 4 Schematic representation of time relations between peak negative dP/dt, mitral valve opening (MVO), peak rate of ventricular volume increase during diastole ( $d V / d t)$, and minimum left ventricular pressure (Pmin) at control and during an episode of angina.

( $\pm 20 \mathrm{~ms}$ ) by angina. These three subjects showed changes resembling those in the other eight subjects in whom heart rate was increased during angina. We therefore conclude that angina directly modifies early as well as late diastolic function in patients with coronary artery disease.

An increase in ventricular end diastolic pressure and an upward shift of the pressure-volume curve are well recognised signs of an episode of myocardial ischaemia, ${ }^{12}$ and they often precede both symptoms or electrocardiographic changes. When end diastolic pressure increases in the absence of significant changes in end diastolic volume, as was the case in our patients, it is often taken as evidence of an increase in myocardial stiffness. This feature has been variously ascribed to delayed deactivation of actin-myosin cross bridges $^{89}$ or to increased myocardial turgor ${ }^{10}$ resulting from the increase in aortic pressure that often accompanies an anginal episode. However, cavity compliance and, still less, myocardial stiffness cannot be estimated from end diastolic values of pressure and volume alone. Myocardial compliance at any point during diastole is represented by the slope of the pressure-volume relation. In this study we used the simplest possible model and assumed that there was a linear relation between left ventricular pressure and volume over the range in which both increased together during late diastole. "We found that although an attack of angina caused an upward shift of the ventricular diastolic pressurevolume curve this was not associated with any consistent change in cavity stiffness assessed from the slope of the pressure-volume relation. This conclusion would not have been altered had we made use of the popular but unproved idea that the passive left ventricular pressure-volume curve is exponential. Shifting passive diastolic pressure-volume relations have been explained in several ways. Pericardial constraint ${ }^{7}$ is a possibility but this mechanism, which would have its predominant effect during late diastole, seems unlikely in our group of patients in whom during late diastole the left ventricle was operating over the same volume range during angina as at control. The left ventricular diastolic pressurevolume relation may be altered by changes in right ventricular shape, volume, or pressure, the effect being modulated by the pericardium or the shared interventricular septum. ${ }^{7}$ For the reasons described above, the pericardial constraint seems unlikely, but we cannot exclude the possibility that a hypothetical disturbance of right ventricular diastolic function contributed to the shift of the pressure-volume relation found in our patients.

The characteristic pattern of falling pressure and 
increasing volume in early diastole has been recognised for many years. ${ }^{23}$ In human beings it has been detected on simultaneous $\mathbf{M}$ mode echocardiograms and pressure measurements ${ }^{24}$ and more recently by angiography. ${ }^{21}$ This behaviour departs widely from any simple passive model, and its mechanism is still uncertain. It has been suggested that it is the result of decay in the active state being prolonged beyond mitral valve opening ${ }^{25}$ so that the fall in active wall tension induced by myocardial relaxation outweighs the increase in passive tension caused by the rise in cavity volume. The time of minimum pressure thus represents equilibrium between these two processes. This explanation thus requires that an episode of angina, which prolongs relaxation, would also delay the time of minimum pressure. But we did not see this in our patients.

The phenomenon of falling pressure associated with rising volume has also been ascribed to the effects of restoring forces (that is to elastic recoil). These forces reside in connective tissue elements within the myocardium. They are energised during systole and then act during diastole to return the ventricle to its pre-contractile configuration. ${ }^{34}$ Their extent is thus likely to be proportional to the distortion of cavity geometry and volume at end systole. Not until pressure and volume start to rise togetherthat is at the time of minimum cavity volume-are their effects outweighed by the passive mechanical properties of the ventricular myocardium. Our results can readily be explained by these ideas. The changes in end systolic volume and shape index are exactly those expected to reduce the forces that restore tension-thus increasing early diastolic pressure and reducing the early diastolic inflow of blood. Asynchronous onset of outward wall motion, commonly seen in angina, may also dissipate these forces and so exacerbate the disturbance. The peak filling rate was little changed by angina; in the face of increased early diastolic ventricular pressure it could only have been maintained by an increase in early diastolic left atrial pressure which would have maintained the corresponding atrioventricular pressure difference. ${ }^{26}$

A normal ejection fraction and a low end systolic volume depend on the presence of longitudinally as well as circumferentially arrayed myocardial fibres. ${ }^{27}$ Whereas circumferential fibres are largely to be found in the mid-wall region, most longitudinally orientated fibres are found subendocardially ${ }^{28}$ and are thus particularly susceptible to the effects of ischaemia. The delay in left ventricular long axis lengthening during early diastole that we saw in our patients is thus a predictable consequence of an attack of angina.

This study illustrates the complex nature of distur- bed left ventricular diastolic function during angina. The upward displacement of the diastolic pressurevolume relation, so often attributed to increased myocardial stiffness, appears as the direct consequence of abnormal early diastolic events. Our results may also have therapeutic relevance. Antianginal drugs often have vasodilator activity. Since such drugs allow end systolic volume to become normal, and since diastolic disturbances are such an important component of the clinical syndrome of angina, it might even be that the mechanisms described here, rather than coronary vasodilatation or reduced systolic wall stress underlie their therapeutic action. Further work is needed to settle these important questions.

\section{References}

1 Rickards AF, Seabra-Gomes R. Observations on the effect of angina on the left ventricle, with special reference to diastolic behavior. Eur $J$ Cardiol 1978;7(suppl):213-38.

2 Mann T, Goldberg S, Mudge GH, Grossman V. Factors contributing to altered left ventricular diastolic properties during angina pectoris. Circulation 1979;59:14-20.

3 Sonnenblick EH. The structural basis and importance of restoring forces and elastic recoil for the filling of the heart. Eur Heart J 1980;1(suppl A):107-10.

4 Caillet D, Crozatier B. Role of myocardial restoring forces in the determination of early diastolic peak velocity of fibre lengthening in the conscious dog. Cardiovasc Res 1982;16:107-12.

5 Waters DD, Da Luz P, Wyatt HL, Swan HJC, Forrester JS. Early changes in regional and global left ventricular function induced by graded reductions in regional coronary perfusion. Am J Cardiol 1977;39:537-43.

6 Kumada T, Karliner JS, Pouleur H, Gallagher KP, Shiratok, Ross J Jr. Effects of coronary occlusion on early ventricular diastolic events in conscious dogs. Am J Physiol 1979;237:H542-9.

7 Glantz SA, Parmley WW. Factors which affect the diastolic pressure-volume curve. Circ Res 1978;42:171-80.

8 Grossman W, Barry WH. Diastolic pressure-volume relations in the diseased heart. Fed Proc 1980;39: 148-55.

9 Brutsaert DL, Rademakers FE, Sys SU. Triple control of relaxation: implications in cardiac disease. Circulation 1984;69:190-6.

10 Salisbury PF, Cross CE, Rieben PA. Influence of coronary artery pressure upon myocardial elasticity. Circ Res 1960;8:794-800.

11 Gibson DG, Prewitt TA, Brown DJ. Analysis of left ventricular wall movement during isovolumic relaxation and its relation to coronary artery disease. $\mathrm{Br}$ Heart J 1976;38:1010-9.

12 Chaitman BR, Bristow JD, Rahimtoola SH. Left ventricular wall motion assessed by using a fixed external reference system. Circulation 1973;48:1043-54. 
13 Rackley CE. Quantitative evaluation of left ventricular function by radiographic techniques. Circulation 1976;54:862-79.

14 Dodge HT, Sandler H, Baxley WA, Hawley RR. Usefulness and limitations of radiographic methods for determining left ventricular volume. Am J Cardiol 1966;18:10-24.

15 Gibson DG, Brown DJ. Continuous assessment of left ventricular shape in man. Br Heart $J$ 1975;37:904-10.

16 Weiss JL, Frederiksen JW, Weisfeldt ML. Haemodynamic determinants of the time-course of fall in canine left ventricular pressure. $J$ Clin Invest 1976;58:751-60.

17 Dawson JR, Gibson DG. Regional left ventricular wall motion in pacing induced angina. $\mathrm{Br}$ Heart $J$ 1988;59:309-18.

18 Carroll JD, Hess DM, Hirzel HD, Krayenbuehl HP. Exercise induced ischemia: the influence of altered relaxation on early diastolic pressures. Circulation 1983;67:521-8.

19 Bourdillon PD, Lorell BH, Mirsky I, Paulus WJ, Wynne J, Grossman W. Increased regional myocardial stiffness of the left ventricle during pacing induced angina in man. Circulation 1983;67:316-23.

20 Mattheos M, Shapiro E, Oldershaw PJ, Sacchetti R, Gibson DG. Non-invasive assessment of changes in left ventricular relaxation by combined phono-, echo-, and mechanocardiography. Br Heart J 1982;47:253-60.

21 Fioretti P, Brower RW, Meester GT, Serruys PW. Interaction of left ventricular relaxation and filling during early diastole in human subjects. Am J Cardiol 1980;46:197-203.

22 Alderman EL, Glantz SA. Acute haemodynamic interventions shift the diastolic pressure-volume curve in man. Circulation 1976;54:662-71.

23 Katz LN. The role played by the relaxation in filling of the ventricle. Am J Physiol 1930;95:542-54.

24 Gibson DG, Brown DJ. Relation between diastolic left ventricular wall stress and strain in man. Br Heart J 1974;36:1066-77.

25 Weisfeldt ML, Armstrong P, Scully HE, Sanders CA, Daggett WM. Incomplete relaxation between beats after myocardial hypoxia and ischemia. J Clin Invest 1974;53:1626-36.

26 Ishida Y, Meisner JS, Tsujioka K, et al. Left ventricular filling dynamics: influence of left ventricular relaxation and left atrial pressure. Circulation 1986;74: 187-96.

27 Sallin EA. Fiber orientation and ejection fraction in the human left ventricle. Biophys $J$ 1969;9:954-64.

28 Greenbaum RA, Ho SY, Gibson DG, Becker AE, Anderson RH. Left ventricular fibre architecture in man. Br Heart J 1981;45:248-63. 